\title{
Socio-economic consequences of globalization on the economic development of regions in the context of security
}

\author{
Viktor Soltes ${ }^{1, *}$, Katarina Repkova Stofkova ${ }^{2}$, and Filip Lenko ${ }^{3}$ \\ ${ }^{1}$ University of Zilina, Faculty of security engineering, Univerzitna 8215/1, 01026 Zilina, Slovakia \\ ${ }^{2}$ University of Zilina, Faculty of operation and economics of transport and communications, \\ Univerzitna 8215/1, 01026 Zilina, Slovakia \\ ${ }^{3}$ University of Zilina, Faculty of security engineering, Univerzitna 8215/1, 01026 Zilina, Slovakia
}

\begin{abstract}
The process of globalization has brought about changes that manifest themselves in different areas of human life. One of the main positive aspects of the process of globalization affecting human quality of life is regional development. This can be measured through selected socioeconomic indicators. However, regional development is not the only aspect that affects human quality of life. The negative aspects of the globalization process, such as illegal migration, have made security aspects more and more influential on quality of life. One of security aspect that negatively affects a human's quality of life, as well as the whole perception of the process of globalization, is migration and related crime committed by foreigners in a particular area. As the objective of the regional development is to promote human quality of life, it is also necessary to deal with the issue of security in this context. The paper deals with the examination of selected socio-economic aspects of regional development in the context of security. The aim of the paper is to reveal relations between selected indicators of regional development in order to increase the stimulation of socio-economic aspects and the level of safety and thus to increase the quality of citizen's life.
\end{abstract}

\section{Introduction}

The process of globalization affects the life of the individual as well as of society as a whole. The manifestations of globalization can be seen in the political, economic, social, cultural, but also in the security sphere. However, the most significant impact of globalization can be seen in the socio-economic field, where globalization is manifested by the opening of national economies, the creation of new jobs, the opening of the national labor market for foreign employees, and thus by reducing unemployment. The creation of new jobs and the arrival of foreign employees also raises the issue of security.

The crime of foreigners has increased in several European Union countries after the opening of the labor market. This is illustrated by several studies carried out in various

\footnotetext{
* Corresponding author: viktor.soltes@fbi.uniza.sk
} 
countries of the European Union, including Germany. That is why it is very important to examine the impact of globalization on economic development in a security context.

\section{Economic dimension of security}

From the economic point of view, security is covered by many scientific disciplines, including the economics of public administration and public finance [1]. In particular, it is an examination of the economic level of security from the point of view of public administration, as ensuring the safety of the population itself is the responsibility of public institutions. From this point of view, experts are looking at the amount of money spent on security, looking for the correlations between security and fiscal policy, but also looking for links between security and the socio-economic situation $[2,3]$.

\subsection{Economic development}

It is difficult to define the term development because it is a vague term that is closely related to economic growth but cannot be linked to it. Economic growth is a basic element of development. Depending on the degree of economic development, regions can be divided into problem regions and developed regions [4]. Depending on their stagnation, problem regions can be further distinguished from structurally disadvantaged (originally developed regions, but at present their main sectors are depressed) and lagging (uninteresting for investments in the long term). In the context of declining economic growth in Europe's democratic countries, the concept of new public management has begun to shape since the 1970s. Its aim was to introduce three economic criteria (economy, efficiency, effectiveness) applied in the business sphere into public administration with the aim of increasing economic growth of countries [5].

From a regional policy point of view, regional development can be defined as a systematic process of positive change that derives from the regions' individual ability to produce comparative advantages and to use the resources available to the region [6].

Regional development is influenced by several aspects of both economic and noneconomic nature. Differences in regions' production factors, differences in economic structure, social capital, low labour mobility, different consumption patterns, demographic characteristics, geographical, historical and natural conditions, educational level of the population, infrastructure facilities are only some of the factors causing different development of regions [7]. Such regional development results in regional disparities, which can be defined as a consequence of a situation where regional development, in particular historical conditions, is unevenly developing regions, resulting in inequalities in social, economic, cultural, infrastructure and other areas [8]. Depending on the area in question, it is possible to distinguish three types of disparities - economic, social and territorial [6]. The components of economic disparities include the economic potential of the region (productivity, performance, and relationships), economic structure (sectoral structure, entity structure), developmental potential (research, development, investment) and human potential (economic activity, employment, unemployment).

\subsection{Security in economic development}

The security situation in the security environment is influenced by many aspects. In regions, the security situation is mainly influenced by indicators of a socio-economic character [9]. 
These indicators can be aggregated according to common features into separate blocks. One option is to break down indicators characterizing the level of socio-economic regional development into aggregate indicators characterizing socio-economic regional development and into indicators characterizing individual spatial structure subsystems. The aggregate indicators include regional GDP, regional GDP per capita, and unemployment rate in \%, average wage, and disposable income. One of the subsystems characterizing the spatial structure is the subsystem of the economic structure of the region. This can be characterized by several indicators, which include the number of large enterprises, non-profit organizations, and the number of visitors to accommodation facilities [6].

These indicators, which can characterize the economic development, can also be used to investigate the security situation. These indicators have a causal relationship with safety indicators. The basic indicator of security in society is crime, which can be understood as a phenomenon disrupting the harmonious development of society [10]. By examining the dependencies between economic and security indicators, it is possible to reveal the relationships between the two spheres and to suggest measures to influence the multiple activities that are reflected in these indicators [11].

\section{Methodology}

Correlation analysis is used to determine the relationship between two or more variables. The strength of this dependence between two quantitative variables is expressed by the correlation coefficient, which takes values from the interval $(-1 ;+1),-1$ being the perfect negative dependence, +1 the perfect positive dependency and 0 the independence of the variables $\mathrm{x}$ and $\mathrm{y}$. There are different correlation coefficients, in practice the most commonly used Pearson correlation coefficient, which is a measure of the linear dependence of two variables [12]. It is calculated according to the formula:

$$
r=\frac{\sum_{i=1}^{N}\left(x_{i}-\bar{x}\right)\left(y_{i}-\bar{y}\right)}{\sqrt{\sum_{i=1}^{N}\left(x_{i}-\bar{x}\right)^{2}\left(y_{i}-\bar{y}\right)^{2}}}
$$

If $r$ is negative, it is indirect, if it is positive, and if $r=0$ there is no statistically detectable linear dependence between the variables. However, the interpretation of the measure of dependence of variables according to the absolute value of the correlation coefficient is different. Different authors state it differently, to deal with its interpretation is ideal after viewing the data in the chart. It is possible to divide the power of dependence into 5 levels [13]:

- if $r \epsilon<1-0,8>$ there is a very strong dependence,

- if $r \epsilon<0,6-0,8)$ there is a strong dependence,

- if $r \epsilon<0,4-0,6)$ there is a medium dependence,

- if $r \epsilon<0,2-0,4)$ there is a weak dependence,

- if $r \epsilon<0-0,2)$ there is a very weak dependence.

\section{Impact of economic development on security}

The study of the impact of the economic development of the region on the safety of the population is possible only after the development of selected economic and security 
indicators has been identified [14]. Economic and security indicators will be examined for the territory of the whole Slovak Republic, which represents the NUTS level 1 region.

To determine the impact and degree of dependence of economic indicators on safety in terms of correlation analysis, individual economic indicators can be considered as independent variables. Crime, which is an indicator of safety, can be chosen as a dependent variable for the purposes of correlation analysis. Among the economic indicators, the selected region will be analysed by regional GDP, regional GDP per capita, net money income of households (NMI), net money expenditure of households (NME), gross monthly wage (GMW), number of enterprises (NE), number of self-employed persons and unemployment rates (S-EP). The dependence of these indicators will be examined not only on total crime (TC), but also on economic crime (EC), which may be most closely related to economic development [6]. Table 1 contains a matrix of correlation dependencies between socio-economic indicators and safety indicators in the Slovak Republic.

Table 1. Matrix of correlation dependencies between socio-economic and safety indicators [15, $16]$.

\begin{tabular}{|l|c|c|c|c|c|c|c|c|c|c|}
\hline \multicolumn{1}{|c|}{ Indikátor } & rGDP & $\begin{array}{c}\text { rGDP } \\
\text { p.c. }\end{array}$ & NMI & NME & GMW & NE & S-EP & NE & EC & TC \\
\hline rGDP & 1,000 & & & & & & & & & \\
\hline rHDP p.c. & 1,000 & 1,000 & & & & & & & & \\
\hline NMI & 0,992 & 0,992 & 1,000 & & & & & & & \\
\hline NME & 0,981 & 0,981 & 0,984 & 1,000 & & & & & & \\
\hline GMW & 0,994 & 0,994 & 0,990 & 0,969 & 1,000 & & & & & \\
\hline NE & 0,968 & 0,969 & 0,968 & 0,924 & 0,982 & 1,000 & & & & \\
\hline S-EP & 0,458 & 0,455 & 0,336 & 0,459 & 0,338 & 0,206 & 1,000 & & & \\
\hline NE & $-0,815$ & $-0,815$ & $-0,866$ & $-0,908$ & $-0,820$ & $-0,734$ & $-0,489$ & 1,000 & & \\
\hline EC & 0,438 & 0,437 & 0,279 & 0,362 & 0,344 & 0,223 & 0,724 & $-0,335$ & 1,000 & \\
\hline TC & $-0,732$ & $-0,734$ & $-0,803$ & $-0,722$ & $-0,774$ & $-0,850$ & 0,177 & 0,563 & 0,254 & 1,000 \\
\hline
\end{tabular}

Based on the above facts from the correlation matrix for the whole territory of the Slovak Republic it can be stated that a strong linear dependence $<0.6 ; 0.8$ ) is located between economic crime and the quantity of sole traders. Medium linear dependence $<0.4$; 0.6 ) is located between economic crime and regional GDP and regional GDP per capita and between total crime and unemployment rate. Weak linear dependence $<0.2 ; 0.4$ ) is between economic crime and net money income and expenditure of households, gross monthly wage and number of enterprises. Very weak linear dependence $<0 ; 0.2)$ is only between the total crime and the number of self-employed.

In the matrix of correlation dependencies, we can also find negative values in addition to positive correlation coefficients. These express an indirect linear relationship between the examined indicators. Strong linear indirect dependence $<-0.6 ;-0.8)$ is between total crime and net money income of households and number of enterprises. Medium linear indirect dependence $<-0.4 ;-0.6)$ is between total crime and regional GDP, regional GDP per capita, net money expenditure of households and gross monthly wage. Weak linear indirect dependence $<-0.2 ;-0.4$ ) is only between economic crime and the unemployment rate.

The above facts show that there are not very strong dependencies between indicators of economic development and crime. Nevertheless, it can be concluded that some dependencies are strong, whether they are direct or indirect linear dependencies. However, 
a significant finding is that while economic crime is directly dependent on selected economic indicators, overall crime is largely indirectly dependent on these indicators.

\section{Conclusion}

Security is currently one of the most discussed issues in society. In the context of globalization, this issue is addressed not only by world political leaders, but also by various international organizations. The consequences of the globalization process are primarily reflected in the economic growth of countries. Secondary impact can also be seen in other spheres, e.g. in cultural, social, but also in security. Although many experts are concerned with security and economic issues, the impact of economic growth on the security of citizens and their property is minimally addressed by the professional community. That is why it is important to examine the impact of economic indicators on safety indicators and to reveal the connections between these areas.

While economic growth can be measured through various economic indicators, the measurement of safety is largely subjective. Objectively, security can be expressed primarily through crime, which is committed at a certain time and place. That is why crime can be considered an objective safety indicator. According to the facts of crime, it is possible to divide crime into several types. One type of crime that is most closely related to economic growth is economic crime.

The correlation analysis can be used to investigate the impact of selected economic indicators on crime (overall and economic). Based on the calculation of correlation coefficients between selected economic and safety indicators, it was found that there is usually a strong to weak dependence between them. The correlation coefficient was positive between selected economic indicators and economic crime, indicating a direct linear dependence. On this basis, we can say that economic growth has a strong to moderate impact on the growth of economic crime. Vice versa, the correlation coefficient between selected economic indicators and total crime was mostly negative, which means an indirect linear dependence between these indicators. These findings can be understood as the overall crime in society decreases with economic growth.

Based on these facts, it can be stated that the secondary effect of economic growth is the reduction of overall crime. The problem is the negative impact of economic growth on economic crime. The most significant value of the correlation coefficient can be noticed between the number of sole traders and the quantity of economic crimes. Public authorities should make greater efforts to educate tradesmen in terms of generally binding legislation in order to avoid a large quantity of crimes against them. One of the solutions to this negative situation would be to create and realize courses, especially for beginning tradesmen, to explain case studies aimed at reducing economic crime committed negligently.

This paper was supported by project VEGA 1/0768/19 and VEGA 1/0755/18.

\section{References}

1. J. H. Henderson, T. Squires, A. Storeygard, D. Weil, The global distribution of economic activity: nature, history, and the role of trade. Quarterly journal of economics 133, 357-406 (2018)

2. A. F. Haughwout, Management of large city regions: designing efficient metropolitan fiscal policies. Journal of regional science 50, 401-421 (2010) 
3. G. A. Vardanyan, O. V. Aivazova, Protection of the rights and legitimate interests of legal persons in criminal proceedings: a correlation of criminal law, criminal procedure and forensic aspects. Russian journal of criminology 13, 498-505 (2019)

4. N. Gennaioli, R. La Porta, F. Lopez-de-Silanes, A. Shleifer, Human capital and regional development. Quarterly journal of economics 128, 105-164 (2013),

5. T. Skica, O. Dvoulety, Quantification of the size of local public administration: empirical study of polish regions. European spatial research and policy 25, 75-92 (2018)

6. E. Vyrostova, Regionalna politika a rozvoj (Iura Edition, Bratislava, 2010)

7. V. Soltes, K. Repkova Stofkova, The economic consequences of crime and other antisocial activities. CBU international conference proceedings (Central Bohemia University, Prague, 2017)

8. J. Suedekum, Regional disparities in small countries. Journal of regional science 46, 1002-1005 (2006)

9. B. Pleggenkuhle, The financial cost of a criminal conviction: context and consequences. Criminal justice and behavior 45, 121-145 (2018)

10. S. Roed-Larsen, J. Stoop, Modern accident investigation - four major challenges. Safety science 50, 1392-1397 (2012)

11. B. R. Ferrall, New perspectives on economic crime. Journal of criminal law \& criminology 95, 1147-1148 (2005)

12. J. Kubas, Z. Stofkova, Application of some research methods to determine the level of safety in municipalities. Education, health and ICT for a transcultural world 237, 242248 (2017)

13. J. Cohen. Statistical Power Analysis for the Behavioral Sciences (Routledge, 2013).

14. J. Peloza, The challenge of measuring financial impacts from investments in corporate social performance. Journal of management 35, 1518-1541 (2009)

15. Statistická rocenka regionov Slovenska 2006 - 2018.

16. Statistika kriminality v Slovenskej republike za rok $2000-2018$. 